\title{
Robot Assisted Trans Axillary Thyroidectomy: A Subcontinent Experience
}

\author{
Sabaretnam Mayilvaganan ${ }^{1}\left[\right.$ - Sapana Bothra ${ }^{1}$
}

Received: 21 May 2018/Accepted: 28 May 2018/Published online: 30 May 2018

(C) Association of Otolaryngologists of India 2018

We read with interest "Robot Assisted Trans Axillary Thyroidectomy: A Subcontinent experience" by Gupta et al. [1]. We congratulate the authors on their "three arm single incision" technique and their results they achieved, even though the numbers are small. We agree with the authors regarding the learning curve and that docking time decreases with time and also minor adjustments to suit Indian patients with different profile when compared to their Korean Counterparts with screen detected malignancies and smaller goiters [2]. We have few queries which many interest future readers.

The authors have mentioned Rs. 35,000 and Rs. 15,000 for Robotic and open hemi thyroidectomy however the Robotic patients would have stayed more in the hospital post-surgery than an uneventful open hem thyroidectomy. Did the authors compare the Total cost for Robotic and open hem thyroidectomies? What was the indication for surgery in patients with FNAC diagnosis of colloid goiter? Did the authors find less of sensation over the tunnel area, which can be sometimes troublesome in female patients? Do the authors feel gasless techniques provide any added advantage over techniques which employ gas [3]?

\section{References}

1. Gupta AK, Kumar A, Singh A, Subash A (2018) Robot assisted trans axillary thyroidectomy: a subcontinent experience. Indian J Otolaryngol Head Neck Surg 1-8

2. Ryu HR, Kang SW, Lee SH, Rhee KY, Jeong JJ, Nam KH, Chung WY, Park CS (2010) Feasibility and safety of a new robotic thyroidectomy through a gasless, transaxillary single-incision approach. J Am Coll Surg 211(3):e13-e19

3. Bhargav PR, Kumbhar US, Satyam G, Gayathri KB (2013) Gasless single incision trans-axillary thyroidectomy: the feasibility and safety of a hypo-morbid endoscopic thyroidectomy technique. J Minimal Access Surg 9(3):116
Sabaretnam Mayilvaganan

drretnam@gmail.com

1 Department of Endocrine Surgery, Sanjay Gandhi Postgraduate Institute of Medical Sciences, Raebareli Road, Lucknow 226 014, India 